\title{
Effect of Erbium:Yttrium-Aluminum-Garnet Laser Combined with Mineralizing Agents on Microhardness of Demineralized Dentin
}

\author{
Hila Hajizadeh ${ }^{1,2}$ Atefeh Nemati-Karimooy ${ }^{1,2}$ Peiman Babaee-Rishkhori ${ }^{3}$ \\ ${ }^{1}$ Department of Restorative and Cosmetic Dentistry, School of \\ Dentistry, Mashhad University of Medical Sciences, Mashhad, Iran \\ ${ }^{2}$ Dental Research Center, Mashhad University of Medical Sciences, \\ Mashhad, Iran \\ Address for correspondence Atefeh Nemati-Karimooy, DDS, MS. \\ Department of Restorative and Cosmetic Dentistry, School of Dentistry, \\ Mashhad University of Medical Sciences, Mashhad, Iran \\ (e-mail: nematika@mums.ac.ir).
}

${ }^{3}$ Department of Restorative Dentistry, Iranian Clinic, Mashhad, Iran

Eur J Dent 2019;13:11-16

\section{Abstract}

\section{Keywords}

- casein phosphopeptide-amorphous calcium phosphate

- demineralized dentin

- erbium: yttriumaluminum-garnet laser

- mineralizing agents
Objective The aim of this study was to assess the combined effect of erbium:yttrium-aluminum-garnet (Er:YAG) laser and mineralizing agents including casein phosphopeptide-amorphous calcium phosphate (CPP-ACP) and fluoride in improving the resistance of demineralized dentin at new demineralization process.

Materials and Methods One hundred and twenty healthy dentin surfaces were prepared and demineralized using acidic solutions. Primary microhardness was measured (h1), and samples were randomly divided into six groups. Each group received a different protocol as follows: Group A (control group): no additional treatment, Group B: applying a fluoridated gel, Group C: applying a CPP-ACP-containing cream, Group D: irradiation of Er:YAG laser, Group E: irradiation of Er:YAG laser combined with the application of a fluoridated agent, and Group F: irradiation of Er:YAG laser combined with the application of CPP-ACP-containing cream. Microhardness values were measured afterward ( $\mathrm{h} 2$ ). Then, all the groups were re-exposed to acidic solution, and microhardness was measured for the third time (h3). The microhardness data were analyzed using analysis of variance and Scheffe's post hoc test.

Results Although application of mineralizing agents increased the microhardness of demineralized dentin in comparison with the control group, no significant difference was observed using two agents. Comparison of laser groups showed an increase in microhardness only after the irradiation of Er:YAG laser combined with the application of a fluoridated agent. Demineralizing process reduced the microhardness values in all the groups, but the application of a CPP-ACP agent caused the least reduction among the laser irradiated groups. Comparison of hardness changes at the beginning and end of the experiment did not show any significant differences between the groups.

Conclusion Comparison of treatment modalities used in this study exhibited that fluoride had the greatest impact on dentin resistance. Laser irradiation on demineralized dentin did not increase the hardness or resistance to acidic attacks.

\section{Introduction}

In tooth preparation, it is desirable to only remove infected dentin, leaving remineralizable affected dentin. ${ }^{1,2}$ Following this protocol, most of the tooth structure can be preserved

during cavity preparation. However, it should be considered that the affected dentin has an intact collagen matrix and no bacteria, but it contains lower mineral content than normal dentin. ${ }^{1,2}$

License terms 
Reinforcing demineralized dentin such that it can tolerate higher levels of acidic challenges might prevent the extension of caries under restoration. ${ }^{3}$ There are some mineralizing agents mostly including fluoride and calcium/ phosphate compositions. ${ }^{4,5}$ One of these materials is casein phosphopeptide-amorphous calcium phosphate (СРP-АCP), a milk-derivative that maintains a supply of bioavailable calcium and phosphate ions for subsurface remineralization. ${ }^{6}$ The use of such materials might compensate the lost mineral content of dentin.

On the other hand, laser irradiation is a new technology in the treatment of dental caries..$^{5}$ In recent years, different types of lasers were assessed either for preventing or arresting tooth caries. ${ }^{5,7}$ Laser irradiation of dental hard tissues can cause different degrees of chemical or morphological changes, which depends on the absorption characteristics of the tissue and the type of laser. ${ }^{9}$ At high doses, the laser removes tooth structure, but it only changes the tissue at doses lower than $60 \mathrm{~mJ}^{10}$; for instance, it enhances enamel resistance against acid attacks. ${ }^{9}$ These changes occur while the possibility of heat damage to the adjacent tissue in short- and long-wavelength laser systems is negligible. ${ }^{10}$ Westerman et $\mathrm{al}^{11}$ and Powell et al ${ }^{12}$ found that enamel and dentin surfaces treated with argon lasers had a higher resistance against demineralization in comparison with nontreated surfaces. Furthermore, other studies have shown that neodymium:yttrium-aluminu m-garnet (Nd:YAG) laser has the ability to reinforce dental surfaces against acid decalcification. ${ }^{13,14}$ Furthermore, $\mathrm{CO}_{2}$ laser increases the resistance of enamel and dentin to caries, and diode laser promotes dentin hardness. ${ }^{15-17}$ Erbium:yttrium-aluminum-garnet (Er:YAG) laser which was first licensed by the Food and Drug Administration in 1997 to be applied on hard tissue has the ability of hard tissue ablation. ${ }^{10,18}$

Furthermore, there are various ideas about the auxiliary mechanisms associated with the application of minerals to enhance tooth mineralization. In some studies, it has been argued that laser radiation before or after fluoride application can increase fluoride intake and decrease solubility of the tooth in an acid solution. These studies suggest that laser radiation leads to more fluoride adhesion to deeper layers of dental hard tissue..$^{8,15,16}$

Although many studies have evaluated the effect of lasers on acid resistance of enamel, ${ }^{10,14,16,18-20}$ there are very few studies considering laser radiation for reinforcing demineralized dentin. ${ }^{21-23}$ However, no studies have yet assessed the combined effect of Er:YAG laser and calciumphosphate-containing materials on the reinforcement of demineralized dentin.

Thus, the aim of this study was to assess the combined effect of Er:YAG laser and mineralizing agents including CPP-ACP and fluoride in improving the resistance of demineralized dentin at new demineralization process. The null hypothesis is that neither the laser nor the mineralizing agents can improve the resistance of dentin for new demineralization process.

\section{Materials and Methods}

\section{Study Design}

One hundred and twenty caries-free human maxillary premolars, extracted for orthodontic reasons, were selected under a protocol approved by the Ethics Committee of Mashhad University of Medical Sciences (IR.mums. sd.REC.1394.180). The teeth were stored in $0.5 \%$ thymol solution at $48^{\circ} \mathrm{C}$ and used within 1 month of extraction. All of the occlusal enamels were removed using a water-cooled low-speed diamond saw. Enamel removal was checked using a stereomicroscope. The teeth were mounted on pink acrylic resin using small plastic tubes, so that a flat dentin surface perpendicular to the long axis of the tooth was achieved.

The exposed dentin was polished with 400 to 1200 grit $\mathrm{SiC}$ paper for 60 seconds under running water. To create artificial caries-affected dentin lesions, all the specimens were subjected to a pH-cycling procedure. The demineralizing solution contained $2.2 \mathrm{mM} \mathrm{NaH}_{2} \mathrm{PO}_{4}$, $2.2 \mathrm{mM} \mathrm{CaCl}_{2}$, and $50 \mathrm{mM}$ acetic acid, adjusted to $\mathrm{pH} \mathrm{4.8,} \mathrm{and}$ the remineralization solution contained $0.9 \mathrm{mM} \mathrm{NaH} \mathrm{PO}_{4}$, $1.5 \mathrm{mM} \mathrm{CaCl}_{2}$, and $0.15 \mathrm{mM} \mathrm{KCl}$, adjusted to $\mathrm{pH}$ 7.0. For 14 days, each specimen was cycled at room temperature for 8 hours in $10 \mathrm{~mL}$ of demineralizing solution and then for 16 hours in remineralizing solution. The solutions were renewed daily. ${ }^{24}$

The dentin surfaces were tested under $50 \mathrm{~g}$ loads for 10 seconds with a micro-Vickers hardness tester (MH3 Model, Koopaco, Iran) to check the demineralization process. Three measurements were done for each sample, and the average of them was considered as surface hardness. Then, the samples were randomly divided into six groups receiving different surface treatments. Group A (control group): The specimens of this group received no additional treatment. Group B: In this group, $2 \%$ neutral sodium fluoride gel (Master-Dent ${ }^{\circledR}$, DENTONICS, North Carolina, USA) was applied on the dentin for 1 minute. Group C: For the specimens of this group, a CPP-ACP-containing cream (MI Paste, GC, Japan) was applied on the surface for 1 minute. Group D: In this group, the dentin surface was irradiated with Er:YAG dental laser (Pluser, LAMBDA SPA, Italy) with spot size of $1 \mathrm{~mm}$, wavelength of $2940 \mathrm{~nm}$, power of $0.40 \mathrm{~W}$, frequency of $10 \mathrm{~Hz}$, and energy output of $40 \mathrm{~mJ}$. The laser was applied using a circular motion for 30 seconds with the beam directed perpendicular to the dentin surface from $5 \mathrm{~mm}$ distance with $0 \%$ water and $0 \%$ air. Group E: For the specimens of this group, first, $2 \%$ fluoridated gel was applied to the dentin surface for 1 minute; then, the Er:YAG dental laser with the same parameters of Group $\mathrm{D}$ was irradiated to the surface, while fluoride gel was in place. Group F: In this group, the Er:YAG laser with the same parameters of Group D was irradiated to the surface 1 minute after applying of CPP-ACP-containing cream.

Afterward, the Vickers microhardness test was performed for all the specimens (h2). To minimize the confounding effect of dentin site between different steps of measurement, we tried to select the micro-Vickers hardness test site as close to the previous site as possible. 
The third microhardness test (h3) was performed after the exposure of the surfaces to demineralizing solution. The microhardness data were used to compare the effectiveness of different treatment modalities.

\section{Statistical Analysis}

The microhardness data ( $\mathrm{h} 1, \mathrm{~h} 2$, and $\mathrm{h} 3$ ) were analyzed using SPSS (IBM Corporation, Armonk, New York, United States) software. The normality of the data was checked using the Kolmogorov-Smirnov test. The one-way analysis of variance (ANOVA) test followed by Scheffe's post hoc test was used to compare the hardness changes of each group in different stages of the study (h1, h2, and h3) and to compare different groups in each step of the study. $p<0.05$ was considered statistically significant.

\section{Results}

The results of the study are presented in two sections.

\section{Comparison of Nonlaser Groups}

The means of microhardness values and the means of microhardness changes in Groups A, B, and C are presented in - Tables 1 and 2 .

Kolmogorov-Smirnov test was not significant $(p>0.05)$ for microhardness values in nonlaser groups at the beginning of the study (h1); hence, these groups were considered homogeneous. The microhardness values increased after treatment modalities (h2) but decreased after the second demineralization protocol (h3).

One-way ANOVA and Scheffe's post hoc tests were used for inter- and intragroup comparisons. Comparison of Groups A, B, and C showed that after applying fluoride and CPP-ACP in Groups B and C, dentin hardness of both groups increased $(\triangle \mathrm{h} 2 \mathrm{~h} 1)$ and significant differences occurred in the surface hardness of Group A (control) with B (fluoride) and C $(\mathrm{CPP}-\mathrm{ACP})(p=0.00)$.
Following demineralization of the samples in the next step, the Vickers microhardness was reduced in all the groups. However, at this stage, $\Delta \mathrm{h} 3 \mathrm{~h} 2$ was only significant between Group B (fluoride) and Group C (CPP-ACP; $p=0.025)$, and none of these two groups were significantly different from the control Group A. Most hardness changes were observed in Group $C(\Delta \mathrm{h} 3 \mathrm{~h} 2=-16.23)$. After accomplishing all the steps $(\Delta \mathrm{h} 3 \mathrm{~h} 1)$, none of the three groups showed significant statistical differences $(p>0.05)$.

In the control Group A, no changes were observed in microhardness at the first stage of the experiment as this group (control) had not received any additional treatments. However, dentin demineralization led to a significant reduction in hardness in the later stages and in general (between the start and end of the study $[\Delta \mathrm{h} 3 \mathrm{~h} 1])$ ).

Regarding B (fluoride) and C (CPP-ACP) groups, the Vickers microhardness had significantly increased after the first stage, but the next demineralization caused a significant decline in hardness values. In general, the hardness of the two groups showed a significant decrease compared with the outset of the experiment $(p<0.001)$. The lowest degree of hardness reduction after demineralizing the samples was observed in Group B (fluoride; $\Delta \mathrm{h} 3 \mathrm{~h} 1=-7.75$ ).

\section{Comparison of Laser Groups}

The means of microhardness values and the means of microhardness changes in Groups D, E, and F are displayed in - Tables 3 and 4.

The Kolmogorov-Smirnov test reflected that the initial microhardness (h1) was not significantly different between the laser groups; hence, these groups were considered homogeneous $(p>0.05)$.

One-way ANOVA and Scheffe's post hoc tests were used for inter- and intragroup comparisons.

Comparison of hardness changes following different treatment modalities showed a significant difference among the three groups, so that the use of laser in

Table 1 Means of microhardness values in nonlaser groups

\begin{tabular}{|l|l|l|l|}
\hline \multirow{2}{*}{ Groups } & Microhardness & h2 & h3 \\
\cline { 2 - 4 } & h1 & $45.92^{\mathrm{B}, \mathrm{a}}$ & $33.92^{\mathrm{C}, \mathrm{b}}$ \\
\hline A (control) & $45.92^{\mathrm{A}, \mathrm{a}}$ & $46.92^{\mathrm{B}, \mathrm{b}}$ & $35.48^{\mathrm{C}, \mathrm{c}}$ \\
\hline B (fluoride) & $43.23^{\mathrm{A}, \mathrm{a}}$ & $46.75^{\mathrm{B}, \mathrm{b}}$ & $30.52^{\mathrm{C}, \mathrm{c}}$ \\
\hline C (CPP-ACP) & $43.04^{\mathrm{A}, \mathrm{a}}$ & & \\
\hline
\end{tabular}

Abbreviation: CPP-ACP, casein phosphopeptide-amorphous calcium phosphate.

Different uppercase letters indicate significant differences in columns; different lowercase letters indicate significant differences in rows.

Table 2 Means of microhardness change $(\Delta h)$ in nonlaser groups

\begin{tabular}{|l|l|l|l|}
\hline \multirow{2}{*}{ Groups } & \multicolumn{2}{l|}{ Microhardness change } & $\Delta \mathrm{h} 3 \mathrm{~h} 1$ \\
\cline { 2 - 4 } & $\Delta \mathrm{h} 2 \mathrm{~h} 1$ & $\Delta \mathrm{h} 3 \mathrm{~h} 2$ & $-12.00^{\mathrm{A}}$ \\
\hline $\mathrm{A}$ (control) & $0.00^{\mathrm{A}}$ & $-12.00^{\mathrm{A}, \mathrm{B}}$ & $-7.75^{\mathrm{A}}$ \\
\hline B (fluoride) & $3.69^{\mathrm{B}}$ & $-11.44^{\mathrm{A}}$ & $-12.52^{\mathrm{A}}$ \\
\hline C (CPP-ACP) & $3.71^{\mathrm{B}}$ & $-16.23^{\mathrm{B}}$ & \\
\hline
\end{tabular}

Abbreviation: CPP-ACP: casein phosphopeptide-amorphous calcium phosphate.

Equal capital letters indicate differences in columns. 
Table 3 Means of microhardness values in laser groups

\begin{tabular}{|l|l|l|l|}
\hline \multirow{2}{*}{ Groups } & Microhardness & h2 & h3 \\
\cline { 2 - 4 } & h1 & $33.18^{\mathrm{A}, \mathrm{a}}$ & $22.25^{\mathrm{A}, \mathrm{b}}$ \\
\hline D (laser) & $34.68^{\mathrm{A}, \mathrm{a}}$ & $41.69^{\mathrm{B}, \mathrm{b}}$ & $26.67^{\mathrm{B}, \mathrm{c}}$ \\
\hline E (laser + fluoride) & $38.89^{\mathrm{A}, \mathrm{a}}$ & $28.67^{\mathrm{A}, \mathrm{b}}$ & $22.58^{\mathrm{A}, \mathrm{c}}$ \\
\hline
\end{tabular}

Abbreviation: CPP-ACP, casein phosphopeptide-amorphous calcium phosphate.

Different uppercase letters indicate significant differences in columns; different lowercase letters indicate significant differences in rows.

Table 4 Means of microhardness change $(\Delta \mathrm{h})$ in laser groups

\begin{tabular}{|l|l|l|l|}
\hline \multirow{2}{*}{ Groups } & \multicolumn{2}{|l|}{ Microhardness change } & $\Delta \mathrm{h} 3 \mathrm{~h} 1$ \\
\cline { 2 - 4 } & $\Delta \mathrm{h} 2 \mathrm{~h} 1$ & $\Delta \mathrm{h} 3 \mathrm{~h} 2$ & $-12.43^{\mathrm{A}}$ \\
\hline $\mathrm{D}$ (control) & $-1.50^{\mathrm{A}}$ & $-10.93^{\mathrm{A}, \mathrm{B}}$ & $-12.22^{\mathrm{A}}$ \\
\hline F (laser +fluoride) & $2.80^{\mathrm{B}}$ & $-15.02^{\mathrm{A}}$ & $-12.79^{\mathrm{A}}$ \\
\hline
\end{tabular}

Abbreviation: CPP-ACP, casein phosphopeptide-amorphous calcium phosphate.

Equal capital letters indicate differences in columns.

combination with fluoride led to increased hardness values, but the use of laser alone or combined with CPP-ACP reduced microhardness.

Following the next demineralization, $\Delta \mathrm{h} 3 \mathrm{~h} 2$ in Group F (laser plus CPP-ACP) was significantly different between Groups D (laser alone) and E (laser plus fluoride; $p=0.04$ and $p=0.00$, respectively), but after performing all the stages of the study, comparison of hardness changes $(\Delta \mathrm{h} 3 \mathrm{~h} 1)$ showed no significant differences among the three groups ( $p>0.05$ ).

In Group D, a reduction in surface hardness was observed in the samples after laser radiation, and subsequently, the surface hardness decreased further after the second demineralization $(p<0.001)$.

In Group E, laser radiation, while the fluoride gel was present on the surface, resulted in a slight but significant increase in the Vickers hardness, but again, demineralization caused a significant reduction in dentin hardness $(p<0.001)$.

While CPP-ACP existed on the surface, laser irradiation produced a significant decrease in surface hardness in Group $\mathrm{F}(\Delta \mathrm{h} 2 \mathrm{~h} 1=-6.70 ; p<0.001)$. In this category, the only treatment that resulted in surface hardening was laser radiation in the presence of fluoride gel $(\Delta \mathrm{h} 2 \mathrm{~h} 1=2.80)$.

\section{Discussion}

Despite the importance of conservative dentistry in the present century, there are few studies in the field of reinforcing the demineralized dentin. Therefore, our study was conducted to evaluate the effect of Er:YAG laser irradiation and mineralizing agents on reinforcing demineralized dentin.In this study, five treatment modalities were compared; among them, the greatest impact was attributed to fluoride and CPP-ACP. This study showed that Er:YAG laser irradiation does not increase dentin surface microhardness and even decreases it in some stages.
Since the reduction in the mineral component of dental tissue in the caries process leads to reduced surface hardness, dentin microhardness is an accepted indicator for determining the amount of mineral matrix in a millimeter square dentin. ${ }^{25}$ In the present study, microhardness measurements were used to estimate the amount of dentin mineral content and its resistance to acidic attacks. ${ }^{26}$ In addition, due to the difficulty in homogenization of dental samples with natural caries, a demineralizing solution made in laboratory based on the study by Kucukyilmaz et al was used in this research. ${ }^{24}$ It should be noted that various protocols have been proposed for in vitro induction of caries lesions on dentin surface. Moron et al stated that the artificial caries lesions of dentin vary considerably from one model to another, which, in turn, may affect the processes of remineralization. ${ }^{27}$

The effect of fluoride and its role in the enhancement of remineralization and inhibition of demineralization have been proven. ${ }^{7,28}$ The mechanism of fluoride effect on enamel is relatively well known. After applying topical fluoride with high concentration, calcium fluoride $\left(\mathrm{CaF}_{2}\right)$ is the main product deposited on the enamel surface and the subsurface layer of enamel caries lesion. Products with low fluoride concentration tend to precipitate as fluoroapatite $\left.\left(\mathrm{Ca}_{10(\mathrm{P}} \mathrm{O}_{4}\right)_{6} \mathrm{~F}_{2}\right)$. While fluoroapatite is bound to the crystalline enamel structure, most of the depositional calcium fluoride deposited on the enamel surface is lost when exposed to alkaline solutions. Under demineralization conditions, which the $\mathrm{pH}$ of the environment reduces, if phosphate ions are present, the fluoride ion released from calcium fluoride will precipitate again in the enamel structure in the form of fluoroapatite. ${ }^{29}$ However, there are very few studies on the effect of fluoride on demineralized dentin., 5,24

In addition to fluoride, the most commonly used product in this field, other compounds with similar applications have been marketed. The CPP-ACP-containing agents form an amorphous and permeable phosphate and calcium ion available to the tooth. These ions, after entering the 
tooth structure, increase the mineral content of the tooth structure and increase its resistance to acid attacks. ${ }^{30}$

Some studies proposed that Er:YAG laser with the ability of hard tissue ablation, if used simultaneously with fluoride compositions, could increase the penetration of ions into small spaces in the enamel and dentin. Furthermore, laser heat can create fine cracks and small spaces that facilitate fluoride penetration. ${ }^{15,16,31}$ It is suggested that the application of fluoride laser combination could transform hydroxyapatite into fluoridated hydroxyapatite and increase fluoride uptake in both enamel and dentin. This process might create a more resistant tooth structure against caries development. 5,18,32

In the present study, Er:YAG laser was irradiated from the 5 -mm distance of the demineralized dentin surface in short pulse mode with the wavelength of $2940 \mathrm{~nm}$, frequency of $10 \mathrm{~Hz}$, power of $0.40 \mathrm{w}$, and energy of $40 \mathrm{~mJ}$ without air and water as a circular motion for 30 seconds. Previous studies have claimed that after laser irradiation with these parameters and without air and water, laser-induced heat melts the dental tissue and converts it to a phase that is more acid resistant. Since Er:YAG laser has a low penetration depth, there is no risk to the pulp and tissue around the teeth. ${ }^{26}$

In this study, after initial demineralization (h1), the groups were divided into two general classes without laser and with laser application. The initial microhardness was similar between the groups of each category.

In nonlaser groups, fluoride and CPP-ACP led to a similar effect on demineralized dentin microhardness. Although the application time of these two compounds was short (1 minute), they could significantly increase dentin hardness. This finding is consistent with other studies, showing that the use of mineral compounds increases the hardness of the dental substrate by deposition on the surface., 4,533

Dentin hardness, which was thus reinforced, was significantly reduced after exposure to demineralization solution, and the hardness was comparable to that of the control group, which had not received any kind of treatment. The addition of fluoride ions and calcium compounds with a 1-minute application time might be only a superficial precipitate, and absorption of minerals might not occur in deep dentin. We believe that if fluoride was added in a durable chemical reaction to dentin structure (similar to the pulp defense against stimuli leading to sclerosing dentin), the results would be expected to vary and an increased resistance to caries process would be possible.

Whether the increase in the fluoride application time or its application along with other methods could cause deeper penetration or stimulate the formation of chemical bonds between mineral ions and dentin substrate remains nebulous. This process is similar to the role of a live pulp in deposition of calcium and phosphorus in dentin. Following the current study, further studies are recommended to measure deep hardness or to use methods for measuring the dentin mineral content after similar treatments.

Another issue studied in this research was the effect of Er:YAG laser alone or with the use of mineralizing compounds on the dentin microhardness. Some studies have shown that the use of Er:YAG laser with some specific radiation characteristics can have a positive effect on the hardness of the surface or deep dentin. ${ }^{21,28}$

In the present study, microhardness evaluation showed that the Er:YAG laser alone with the parameters used in this study could not improve the hardness of demineralized dentin, and hardness of the dentin that was exposed to laser radiation significantly decreased during the second demineralization. In other words, according to our findings, Er:YAG laser alone does not lead to increased dentin resistance to caries. Many studies have also shown similar results following Er:YAG laser application on dentin hardness or dentin reinforcement against chemical demineralization. . $2,26,34,35$

In a study by Malkoç and Sevimay, the use of three compounds including oxalate, resin, and glutaraldehyde with Nd:YAG laser did not change the dentin calciumphosphate ratio, while following the laser radiation without any additional treatment, the dentin calcium-phosphate ratio decreased. ${ }^{36}$ However, in our study, the combination of Er:YAG laser with mineralizing compounds resulted in different findings, so that laser irradiation in the presence of fluoride increased dentin microhardness, which is probably due to the effect of fluoride on dentin. On the other hand, laser irradiation surprisingly reduced hardness when CPP-ACP was on the dentine surface. Probably, the deposition of this compound at the surface creates a soft unstructured layer, and the hardness number is related to this surface layer. To clarify these findings, more investigations are recommended to study different compounds or hardness of deeper areas.

\section{Conclusion}

Comparison of treatment modalities used in this study exhibited that applying the fluoride gel has the greatest impact on dentin resistance against acidic challenges. Er:YAG laser irradiation on demineralized dentin did not increase the hardness or resistance to acidic attacks. All in all, although some of the treatment modalities used in this study slightly enhanced dentin hardness, they were not effective in increasing resistance against the second demineralization.

\section{Financial Support and Sponsorship}

This research project was funded by the Research Council of Mashhad University of Medical Sciences (MUMS).

\section{Conflicts of Interest}

None declared.

\section{Acknowledgments}

The authors would like to thank the Dental Research Committee at MUMS. Furthermore, it should be noted that this article was extracted from thesis number 2923.

\section{References}

1 Fusayama T. Two layers of carious dentin; diagnosis and treatment. Oper Dent 1979;4(2):63-70

2 Zanchi $\mathrm{CH}$, Lund RG, Perrone LR, et al. Microtensile bond strength of two-step etch-and-rinse adhesive systems on sound and artificial caries-affected dentin. Am J Dent 2010;23(3):152-156 
3 Fusayama T. Factors and prevention of pulp irritation by adhesive composite resin restorations. Quintessence Int 1987;18(9):633-641

4 Hosoya Y, Watanabe E, Tadokoro K, Inoue T, Miyazaki M, Tay FR. Effects of ammonium hexafluorosilicate application on demineralized enamel and dentin of primary teeth. J Oral Sci 2012;54(3):267-272

5 Mei ML, Chu $\mathrm{CH}$, Low $\mathrm{KH}$, Che CM, Lo EC. Caries arresting effect of silver diamine fluoride on dentine carious lesion with S. mutans and L. acidophilus dual-species cariogenic biofilm. Med Oral Patol Oral Cir Bucal 2013;18(6):e824-e831

6 Nongonierma AB, Fitzgerald RJ. Biofunctional properties of caseinophosphopeptides in the oral cavity. Caries Res 2012;46(3):234-267

7 Chin-Ying SH, Xiaoli G, Jisheng P, Wefel JS. Effects of CO2 laser on fluoride uptake in enamel. J Dent 2004;32(2):161-167

8 Ana PA, Tabchoury CP, Cury JA, Zezell DM. Effect of Er, Cr:YSGG laser and professional fluoride application on enamel demineralization and on fluoride retention. Caries Res 2012;46(5):441-451

9 Rohanizadeh R, LeGeros RZ, Fan D, Jean A, Daculsi G. Ultrastructural properties of laser-irradiated and heat-treated dentin. J Dent Res 1999;78(12):1829-1835

10 Bevilácqua FM, Zezell DM, Magnani R, da Ana PA, Eduardo CdeP. Fluoride uptake and acid resistance of enamel irradiated with Er:YAG laser. Lasers Med Sci 2008;23(2):141-147

11 Westerman GH, Hicks MJ, Flaitz CM, Blankenau RJ, Powell GL, Berg JH. Argon laser irradiation in root surface caries: in vitro study examines laser's effects. J Am Dent Assoc 1994;125(4):401-407

12 Powell GL, Morton TH, Whisenant BK. Argon laser oral safety parameters for teeth. Lasers Surg Med 1993;13(5):548-552

13 Zezell DM, Boari HG, Ana PA, Eduardo CdeP, Powell GL. Nd:YAG laser in caries prevention: a clinical trial. Lasers Surg Med 2009;41(1):31-35

14 Azevedo DT, Faraoni-Romano JJ, Derceli JdosR, Palma-Dibb RG. Effect of Nd:YAG laser combined with fluoride on the prevention of primary tooth enamel demineralization. Braz Dent J 2012;23(2):104-109

15 Esteves-Oliveira M, Zezell DM, Ana PA, Yekta SS, Lampert F, Eduardo CP. Dentine caries inhibition through $\mathrm{CO}(2)$ laser $(10.6 \mu \mathrm{m})$ irradiation and fluoride application, in vitro. Arch Oral Biol 2011;56(6):533-539

16 Anaraki SN, Serajzadeh M, Fekrazad R. Effects of laser-assisted fluoride therapy with a CO2 laser and Er, Cr:YSGG laser on enamel demineralization. Pediatr Dent 2012;34(4):e92-e96

17 Viapiana R, Sousa-Neto MD, Souza-Gabriel AE, Alfredo E, Silva-Sousa YT. Microhardness of radicular dentin treated with 980-nm diode laser and different irrigant solutions. Photomed Laser Surg 2012;30(2):102-106

18 Liu Y, Hsu CY, Teo CM, Teoh SH. Potential mechanism for the laser-fluoride effect on enamel demineralization. J Dent Res 2013;92(1):71-75

19 Asl-Aminabadi N, Najafpour E, Samiei M, et al. Laser-Casein phosphopeptide effect on remineralization of early enamel lesions in primary teeth. J Clin Exp Dent 2015;7(2):e261-e267

20 Fekrazad R, Ebrahimpour L. Evaluation of acquired acid resistance of enamel surrounding orthodontic brackets irradiated by laser and fluoride application. Lasers Med Sci 2014;29(6):1793-1798
21 Chinelatti MA, Raucci-Neto W, Corona SA, Palma-Dibb RG. Effect of erbium:yttrium-aluminum-garnet laser energies on superficial and deep dentin microhardness. Lasers Med Sci 2010;25(3):317-324

22 Dilber E, Malkoc MA, Ozturk AN, Ozturk F. Effect of various laser irradiations on the mineral content of dentin. Eur J Dent 2013;7(1):74-80

23 Passos VF, Melo MA, Silva FF, Rodrigues LK, Santiago SL. Effects of diode laser therapy and stannous fluoride on dentin resistance under different erosive acid attacks. Photomed Laser Surg 2014;32(3):146-151

24 Kucukyilmaz E, Savas S, Akcay M, Bolukbasi B. Effect of silver diamine fluoride and ammonium hexafluorosilicate applications with and without Er:YAG laser irradiation on the microtensile bond strength in sound and caries-affected dentin. Lasers Surg Med 2016;48(1):62-69

25 Arbabzadeh F, Birang E, Nazem R, Abbasian M, Koosha F, Birang R. A comparative study on micro hardness and structural changes of dentin floor cavity prepared by Er: YAG laser irradiation and mechanical bur. J Dent (Shiraz) 2013;14(2):73-77

26 Tabatabei MH, Arami S, Khajavi F, Moradi Z. Effect of type of cavity preparation (bur, Er:YAG laser) and restorative materials on prevention of caries lesion. J Dent Med 2017;29:229-236

27 Moron BM, Comar LP, Wiegand A, et al. Different protocols to produce artificial dentine carious lesions in vitro and in situ: hardness and mineral content correlation. Caries Res 2013;47(2):162-170

28 Souza-Gabriel AE, Chinelatti MA, Pecora JD, Palma-Dibb RG, Corona SA. Dentin microhardness and subsurface morphology after Er:YAG laser cavity preparation using different parameters. J Dent Child (Chic) 2009;76(1):58-66

29 Ekambaram M, Itthagarun A, King NM. Comparison of the remineralizing potential of child formula dentifrices. Int J Paediatr Dent 2011;21(2):132-140

30 Nozari A, Rafiee A, Dehghan Khalili S, Fekrazad R. A comparative evaluation of APF gel, CPP/ACP paste alone and in combination with carbon dioxide laser on human enamel resistance to acid solubility using atomic absorption spectrometry: an in-vitro study. Minerva Stomatol 2018;67(2):68-73

31 Ana P, Bachmann L, Zezell D. Lasers effects on enamel for caries prevention. Laser Phys 2006;16:865-875

32 Gao XL, Pan JS, Hsu CY. Laser-fluoride effect on root demineralization. J Dent Res 2006;85(10):919-923

33 Sinfiteli PP, Coutinho TCL, Oliveira PRA, et al. Effect of fluoride dentifrice and casein phosphopeptide-amorphous calcium phosphate cream with and without fluoride in preventing enamel demineralization in a $\mathrm{pH}$ cyclic study. J Appl Oral Sci 2017;25(6):604-611

34 Chinelatti MA, Rocha CT, Colucci V, Serra MC, Rodrigues-Júnior AL, Corona SA. Effect of Er:Yag laser on dentin demineralization around restorations. Lasers Med Sci 2017;32(2):413-418

35 Malkoc MA, Taşdemir ST, Ozturk AN, Ozturk B, Berk G. Effects of laser and acid etching and air abrasion on mineral content of dentin. Lasers Med Sci 2011;26(1):21-27

36 Malkoç MA, Sevimay M. Evaluation of mineral content of dentin treated with desensitizing agents and neodymium yttrium-aluminium-garnet (Nd:YAG) laser. Lasers Med Sci 2012;27(4):743-748 